\title{
Analisis Wacana Kritis Komodifikasi Budaya Lokal pada Iklan Televisi \\ (Studi Kasus Produk Frestea versi Hiphop Wedding)
}

\author{
Andika Indrayana \\ Program Studi Desain Komunikasi Visual \\ FSR ISI Yogyakarta \\ andikaindrayana@icloud.com
}

\begin{abstract}
This paper aims to reveal local culture's commodification of Frestea TV commercial using critical discourse analysis. Two main concepts of analysis were developed; micro structure and social contexts. Micro structure seeks the representation of the commodity, which based on verbal and visual elements. Verbal includes: theme, scheme, background, details, purpose, coherence, form of sentences, pronouns, lexical, and graphics. Visual includes: visual rhetoric and layout. Research finding shows that Frestea uses Solo's wedding and hiphop culture as commodification, both mixed with parody concept. Also, in relation with social contexts, research results in the finding that the message of the ads do not represent the 'real' value of the local culture, which can lead to create delusion to the consumer.
\end{abstract}

Keywords: Commodification, Local Culture, Frestea, TV Commercial, Critical discourse analysis.

Relevance to Visual Communication Design Practice: This paper can be used as a creative concept development, especially when using local culture as commodification.

\section{PENDAHULUAN}

Komodifikasi, menurut Barker (2005), berasal dari dua akar kata yang berbeda: "komoditas" dan "modifikasi". Menurut istilah yang lazim dipakai dalam kajian budaya, adalah proses yang diasosiasikan dengan kapitalisme di mana objek, kualitas, dan tanda-tanda diubah menjadi komoditas, yaitu sesuatu yang tujuan utamanya adalah untuk dijual di pasar. Akibat ekonomi uang yang berdasarkan atas spirit menciptakan keuntungan sebanyakbanyaknya mengakibatkan munculnya komodifikasi di berbagai sektor kehidupan, termasuk pula di dalam ranah televisi, seperti iklan. Iklan masa kini, dalam pandangan Odih (2007) merupakan wahana primer (primary vehicle) dalam mentransformasi wilayah budaya ke dalam teritori baru kaitannya dengan reproduksi komoditas.
Menurut Bungin (2011) bahwa iklan televisi adalah media pemilik produk yang diciptakan oleh biro iklan, kemudian disiarkan televisi dengan berbagai tujuan, di antaranya sebagai informasi produk dan mendorong penjualan. Oleh karena itu iklan televisi harus memiliki segmen berdasarkan pilihan segmen produk, untuk memilih strategi media, agar iklan itu sampai kepada sasaran. Sajian iklan televisi yang disuguhkan pun bervariasi, ada yang menggunakan pendekatan persuasif-normatif semata, ada yang menggunakan budaya pop, dan tidak jarang pula melakukan komodifikasi budaya lokal sebagai strategi penyampaian pesan.

Namun demikian, praktik komodifikasi pada iklan televisi-terutama dengan pendekatan budaya lokal-seringkali hanya digunakan sebagai pendongkrak penjualan 
produk semata, dan tidak mempertimbangkan berbagai aspek yang terkandung pada budaya tersebut untuk direpresentasikan dan/atau dikreasikan melalui iklan, seperti nilai, makna, maupun relevansinya. Sebagai contoh adalah penelitian yang dilakukan oleh Yoyoh Hareyah mengenai iklan produk Kuku Bima Energi versi Tari Sarojo. (http://komunikasi.unsoed.ac.id/sites/default/ files/72.yoyoh\%20hereyah-umb-final.pdf.

Diakses Oktober 2015). Pada penelitian tersebut diketahui bahwa penggunaan tari Sajojo sebagai salah satu budaya Papua tidak memiliki relevansi dengan konsep keperkasaan yang hendak disampaikan oleh produk, karena tari Sajojo merupakan tari pergaulan yang menceritakan sosok perempuan cantik Papua yang memikat para pecintanya agar tertarik menari bersama dia.

Tak jarang, praktik komodifikasi budaya lokal yang dilakukan oleh iklan berujung pada penilaian masyarakat terhadap konsep dari iklan, yang seringkali dituliskan pada berbagai situs, sebagai bentuk kepedulian akan budaya lokal yang direpresentasikan pada iklan. Sebagai contoh, adalah kritik yang diajukan oleh Agung Soni melalui situs kompasiana.com yang menilai iklan produk Frestea versi Hiphop Wedding tidak merepresentasikan kesesuaian budaya adat Jawa yang sebenarnya, bahkan dianggap merusak konsep-konsep pakem yang terdapat pada budaya tersebut. (http://www.kompasiana.com/takutpadaallah-/iklan-hiphop-wedding-frestealecehkan-budayajawa_54f4a8a97455139e2b6c8be7. Diakses Oktober 2015).
Melalui kedua contoh di atas, dapat diketahui bahwa strategi komodifikasi budaya lokal yang divisualkan melalui iklan, selalu 'bernegosiasi' dengan wacana yang terdapat di ruang sosial; nilai atau makna mengenai visual iklan tersebut. Ketika visualitas iklan 'melenceng' atau tidak memiliki relevansi yang sesuai, maka dapat mendorong suatu kontroversi, wacana baru atau bahkan mendorong perilaku-perilaku yang meniru cerita atau konsep suatu iklan. Hal tersebut diyakini oleh Williamson dalam Gee dan Handford (2012) yang mengatakan bahwa iklan dapat memungkinkan dalam bertanggungjawab dan mengancam nilai-nilai sosial. Iklan dalam hal ini, dapat mendorong suatu pesan yang menipu (deceitful) atau khayalan (delusion) pada konsumen, yang mengakibatkan ketidaksukaan pada dunia nyata dan mencari realitas pengganti.

Melalui pendekatan analisis wacana kritis, tulisan ini bertujuan untuk mengurai struktur mikro komodifikasi budaya lokal sebagai strategi penyampaian pesan yang terdapat pada produk Frestea versi Hiphop Wedding, dan melihat relasinya dengan konteks sosial.

\section{Analisis Wacana Kritis}

Wacana menurut van Dijk (2014) merupakan bentuk interaksi sosial dan, di waktu yang sama, adalah ekspresi dan reproduksi pengetahuan sosial (social cognition). Analisis wacana kritis (AWK) menurut van Dijk dalam Saragih (2015) adalah sebuah upaya atau proses (penguraian) untuk memberi penjelasan dari sebuah teks (realitas sosial) yang mau atau sedang dikaji oleh seseorang atau kelompok dominan yang kecenderungannya mempunyai tujuan 
tertentu untuk memperoleh apa yang diinginkan.

Menurut van Dijk, penelitian atas wacana tidak cukup hanya didasarkan pada analisis teks semata, melainkan juga perlu dilihat bagaimana teks diproduksi. Penelitian mengenai wacana tidak bisa mengeksekusi seakan-akan teks adalah bidang kosong, sebaliknya ia adalah bagian kecil dari struktur besar masyarakat. Wacana oleh van Dijk digambarkan memiliki tiga dimensi: teks, kognisi sosial, dan konteks sosial. Dalam dimensi teks, yang diteliti adalah bagaimana struktur teks dan strategi wacana yang dipakai untuk menegaskan suatu tema tertentu. Pada level kognisi sosial dipelajari proses produksi teks berita yang melibatkan kognisi individu dari wartawan. Sedangkan aspek ketiga yaitu konteks mempelajari bangunan wacana yang berkembang dalam masyarakat akan suatu masalah.

Van Dijk melihat suatu teks terdiri atas beberapa struktur atau tingkatan yang masing-masing bagiannya saling mendukung. Ada tiga tingkatan atau struktur teks. Pertama, struktur makro, yakni makna global atau umum dari suatu teks yang dapat diamati dengan melihat topik atau tema yang dikedepankan dalam suatu berita. Kedua, superstruktur, yang merupakan struktur wacana yang berhubungan dengan kerangka suatu teks, bagaimana bagian-bagian teks tersusun ke dalam berita secara utuh. Ketiga, struktur mikro, yakni makna wacana yang dapat diamati dari bagian kecil suatu teks yang meliputi kata, kalimat, proposisi, anak kalimat, parafrase, dan gambar.

\section{SKEMA NARASI IKLAN DAN ANALISA}

Narasi berupa data verbal dan visual berikut analisa komodifikasi budaya lokal pada iklan Frestea versi Hiphop wedding dibagi menjadi lima tabel untuk kemudahan dalam identifikasi dan analisis, yang akan dijelaskan melalui di bawah ini.

Tabel 1 Identifikasi data verbal dan visual iklan Frestea versi Hiphop wedding

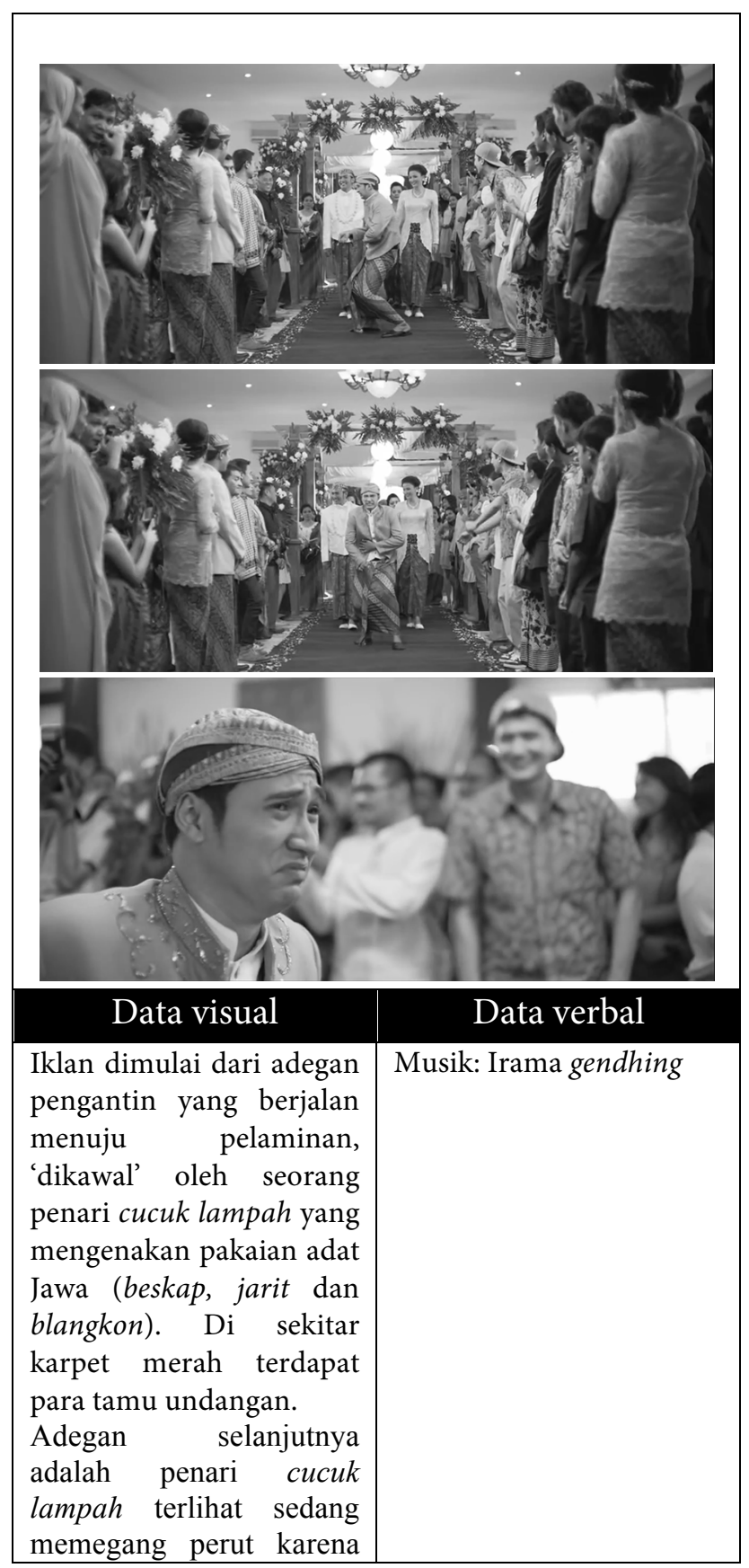


sakit, dan tiba-tiba

'keluar' dari barisan dan

menuju ke arah laki-laki

yang berada di jajaran

tamu undangan yang

memakai topi hijau.

Analisa: Pengantin pria yang mengenakan pakaian model beskap, berdasi kupu-kupu, dan blangkon sebagai penutup kepala, dan pengantin wanita mengenakan kebaya dan stagen. Gaya rambut pengantin wanita berupa model sanggul, dengan hiasan berupa mahkota dan bunga melati. Pengantin pria juga tampak mengenakan kalung bunga melati. Pakaian atas keduanya didominasi warna putih dan bagian bawah berupa jarit batik dengan motif yang sama. Kedua pengantin juga memakai jenis sepatu yang sama yaitu model selop berwarna putih.

Model pakaian yang dikenakan oleh pengantin mengindikasikan model Jawa Tengah, yaitu Solo. Pada pengantin pria, ciri tersebut terlihat dari model blangkon sebagai penutup kepala dan pakaian beskap. Blangkon model Solo, pada bagian belakang memiliki bentuk yang pipih/trepres/kempes, berbeda dengan model Yogyakarta yang memiliki ciri khas berupa mondolan atau tonjolan di bagian belakang yang sangat terlihat jelas. Dalam kesejarahannya, model blangkon Solo berbeda dengan model Yogyakarta karena pada masa lalu, Solo dekat dengan pemerintahan kolonial, sehingga orang-orang Solo sudah terlebih dahulu mengenal cukur. Jadi blangkon Solo hanya mengikatkan 2 pucuk ikatan menjadi satu. Dua ikatan ini ibarat 2 kalimat syahadat yang harus diikat kuat, dipegang teguh di dalam hidup. Meskipun kedua model memiliki bentuk yang berbeda, namun keduanya memiliki dua makna filosofis yang sama. Pertama, blangkon diletakkan di kepala agar produk yang dihasilkan kepala yaitu berupa ide, pemikiran, konsep haruslah tetap selalu dalam koridor nilai-nilai agama Islam. Jadi tidak dibiarkan bebas begitu saja akan tetapi diarahkan agar menjadi berkah untuk sesama. Menjadi rahmatan lil alamin (rahmat untuk seluruh semesta). Filosofi yang kedua blangkon ibarat makrokosmos (Pemilik alam semesta) sedangkan kepala adalah mikrokosmos yaitu makhluk bernama manusia. Artinya dalam menjalankan amanahnya sebagai khalifah fil ardhi (pemimpin di Bumi) harus selalu tunduk dan patuh kepada penciptanya yaitu sang Khalik. ${ }^{1}$ Dalam hal ini, blangkon merupakan sebuah simbol yang memiliki makna filosofis yang dalam.

Model pakaian beskap adalah model langenharjan berwarna putih, yang dikombinasikan dengan kemeja dan dasi kupu-kupu dengan warna yang sama. Ciri khas dari model ini adalah di bagian depan terbuka seperti layaknya baju jas, dengan dasi kupu-kupu, sedangkan bagian belakang seperti beskap memakai keris. Jenis pakaian tersebut kini menjadi kebangsaan masyarakat Surakarta dan sekitarnya dan dijadikan jenis pakaian dari mempelai pria. ${ }^{2}$ Baju pengantin pria model Solo ini, memiliki perbedaan dengan model Yogyakarta, yaitu pada bagian kancing. Pada model Solo, posisi kancing berada di bagian samping, sedangkan model Yogyakarta berada lurus dari atas ke bawah. Menurut sejarah, busana langenharjan diciptakan oleh Mangkunegaran VII ketika

http://alfandiv.blogspot.co.id/2011/10/perbedaan-busana-adatantara-jogjakarta.html. Diakses 22 Oktober 2015.

2 http://kekunaan.blogspot.co.id/2012/07/beskap-langenharjan.html. Diakses 22 Oktober 2015. 
beliau menghadap Sri Susuhunan Paku Buwana IX di Pesanggrahan Langenharjan. Nama Langenharjan diberikan oleh Sri Susuhunan Paku Buwana IX pada busana yang diciptakan oleh Sri Paduka Mangkunegara. Dewasa ini busana Langenharjan dikenakan oleh pengantin pria selama upacara Sang-keran. ${ }^{3}$

Busana pengantin wanita adalah pakaian kebaya panjang model lace dengan model rambut bokor mengkurep (bokor tengkurep), berhias ronce bunga melati dan bunga kanthil di bagian kiri dan kanan, dan diperindah dengan perhiasan berupa gunungan dan cundhuk menthul sebanyak 3 buah di bagian atas konde. Kebaya panjang lace merupakan salah satu alternatif busana pengantin selain model kebaya panjang klasik yang berbahan beludru berhias sulaman-sulaman berwarna emas ataupun busana model basahan yang telah menjadi ikon busana pengantin Solo. Pada mulanya, kebaya panjang hanya berwarna putih, namun sekarang banyak pengantin Solo Putri menggunakan kebaya lace aneka warna. ${ }^{4}$ Penggunaan baju kebaya model lace dapat diartikan bahwa iklan berupaya untuk menampilkan sisi kedinamisan gaya berbusana pengantin yang terjadi di dalam budaya pernikahan adat Solo.

Dalam tata rias model Jawa Tengah (Solo maupun Yogyakarta), pengantin wanita secara umum memakai riasan di bagian kening yang disebut prada. Model Solo memiliki bentuk prada yang melengkung sedangkan gaya Yogyakarta dengan bentuk prada meruncing. Riasan prada berupa

\footnotetext{
3 http://www.karatonsurakarta.com/busanajawa.html. Diakses 22 Oktober 2015.

$4 \quad$ http://alfandiv.blogspot.co.id/2011/10/perbedaan-busana-adatantara-jogjakarta.html. Diakses 22 Oktober 2015.
}

lengkungan besar yang dibuat di tengah, dan diapit oleh lengkungan-lengkungan kecil. Lengkungan besar adalah simbol kebesaran Tuhan. Sedangkan lengkungan yang kecil disebut pengapit. Sebagai simbol bahwa istri nanti harus siap menjadi penyeimbang dalam rumah tangga. Selain itu, di dalam lengkungan tersebut terdapat tiga titik. Titik ini sebagai simbol Trimurti (Dewa Brahma, Dewa Wisnu dan Dewa Siwa). Selain prada, pengantin wanita juga seringkali merias alisnya dengan bentuk seperti tanduk rusa, yang disebut alis menjangan. ${ }^{5}$ Pada iklan, riasan prada maupun alis menjangan tidak tampak di pengantin wanita, hal tersebut dapat diartikan: Pertama, iklan berupaya untuk menampilkan paes atau tata rias pada pengantin wanita dengan gaya yang berbeda. Dengan kata lain, iklan berupaya untuk memodifikasi suatu budaya yang telah ada. Kedua, iklan hanya berupaya untuk menampilkan suasana prosesi pernikahan model Solo, tanpa perlu menampakkan detail yang seharusnya ada dalam suasana tersebut, yang dalam hal ini adalah riasan prada maupun alis menjangan.

Pengantin berjalan di atas karpet berwarna merah diikuti oleh enam orang yang memakai pakaian dengan motif yang sama. Pada iklan ini, ditampilkan sebanyak enam orang, yaitu 2 orang perempuan di belakang pengantin, diikuti 2 orang laki-laki, dan 2 orang berusia muda (laki-laki dan perempuan). Dalam budaya pernikahan Jawa, para pengiring yang berjalan di belakang pengantin adalah keluarga besar mempelai. Besar kemungkinan para pengiring pada iklan

\footnotetext{
5 http://www.isigood.com/wawasan/penting-tahukah-kamu-maknamendalam-riasan-paes-ageng-bagi-perempuan/. Diakses 22 Oktober 2015.
} 
ini secara berurutan adalah ibu, ayah, dan saudara dari kedua mempelai. Penggunaan iringan ini dapat diartikan bahwa iklan berupaya untuk menguatkan kesan budaya pernikahan adat Solo.

Di depan iring-iringan pengantin, tampak seorang laki-laki yang mengenakan pakaian beskap berwarna hijau, blangkon, dan bawahan berupa jarit motif batik dengan sepatu model selop berwarna hitam. Dalam budaya pernikahan adat Jawa Tengah, seseorang yang berjalan di depan iringiringan pengantin disebut suba manggala sebagai cucuk lampah. Tugas suba manggala dalam prosesi pernikahan adalah pembuka jalan terdepan yang melangkahkan kaki dengan gerak tari mengikuti iringan gamelan. Secara umum, tarian juga dilakukan sebagai bentuk tolak bala, atau metafora pengusiran elemen-elemen negatif yang berada di sekitar pengantin. Adanya iring-iringan pengantin dan suba manggala dalam iklan ini dapat diartikan sebagai elemen untuk menguatkan kesan budaya Jawa Tengah selain pengantin.

Suara musik pengiring pengantin berasal dari alat musik gamelan. Dalam suatu acara pernikahan adat Jawa Tengah (Solo dan Yogyakarta), musik gamelan seringkali digunakan untuk menghibur tamu undangan. Musik gamelan dalam budaya pernikahan Jawa Tengah cenderung memiliki irama yang pelan, berbeda dengan irama gamelan Bali yang memiliki tempo lebih cepat. Penggunaan irama gamelan Jawa Tengah sebagai musik latar dapat diartikan: Pertama, menguatkan kesan budaya pernikahan adat Solo melalui musik, selain pengantin iringiringan dan suba manggala. Kedua, menampakkan unsur-unsur lokalitas dalam budaya pernikahan masa kini, yang mulai terganti oleh musik yang lebih modern seperti elekton, dangdut atau band.

Adegan sosok suba manggala yang terlihat sedang memegang perut dengan mimik wajah yang mengindikasikan kondisi tidak sehat, yang tiba-tiba keluar dari barisan, menuju ke arah temannya dan mendorongnya keluar dari barisan tamu. Adegan ini dapat diartikan: Pertama, iklan berupaya untuk menghilangkan suasana sakral yang terjadi di dalam prosesi pernikahan adat Jawa Tengah karena suba manggala tiba-tiba meninggalkan iringan pengantin karena sakit. Kedua, iklan berupaya menekankan konsep hiperbola, atau kesan melebih-lebihkan, agar sesuai dengan konsep cerita yang dibangun yaitu suatu kondisi yang tak terduga.

Sosok teman yang didatangi oleh suba manggala dan dipasangi busana berupa blangkon dan beskap adalah aktor FTV dan selebriti muda bernama Firly Firlana Shihab. Sosok Firly dalam iklan ini memakai topi berwarna hijau dengan posisi terbalik, baju batik, celana kain formal, dan sepatu jenis sneakers sehingga berkesan muda. Selebritis dalam iklan banyak digunakan untuk mengembangkan citra positif produk baru atau mengubah citra produk yang sudah ada, karena untuk melakukan hal ini selebritis mempunyai kekuatan karena mereka menjadi idola banyak orang. ${ }^{6}$ Selain itu, endorser dengan tampilan fisik yang baik dan/atau karakter non-fisik yang menarik dapat menunjang iklan dan dapat menimbulkan minat audience untuk menyimak iklan. ${ }^{7}$

\footnotetext{
http://www.academia.edu/8946447/endorser_dalam_periklanan. Hlm. 6. Diakses 22 Oktober 2015.

http://www.academia.edu/8946447/endorser_dalam_periklanan. Hlm. 8. Diakses 22 Oktober 2015.
} 
Adanya Firly sebagai endorser beserta gaya busananya dapat diartikan: Pertama, iklan memiliki segmen pasar anak muda. Kedua, iklan berupaya menciptakan nuansa kedinamisan budaya, yaitu perpaduan antara budaya tradisional dan budaya modern, yang dalam hal ini diwakili oleh gaya busana Firly.

Tabel 2 Identifikasi data verbal dan visual iklan Frestea versi Hiphop wedding

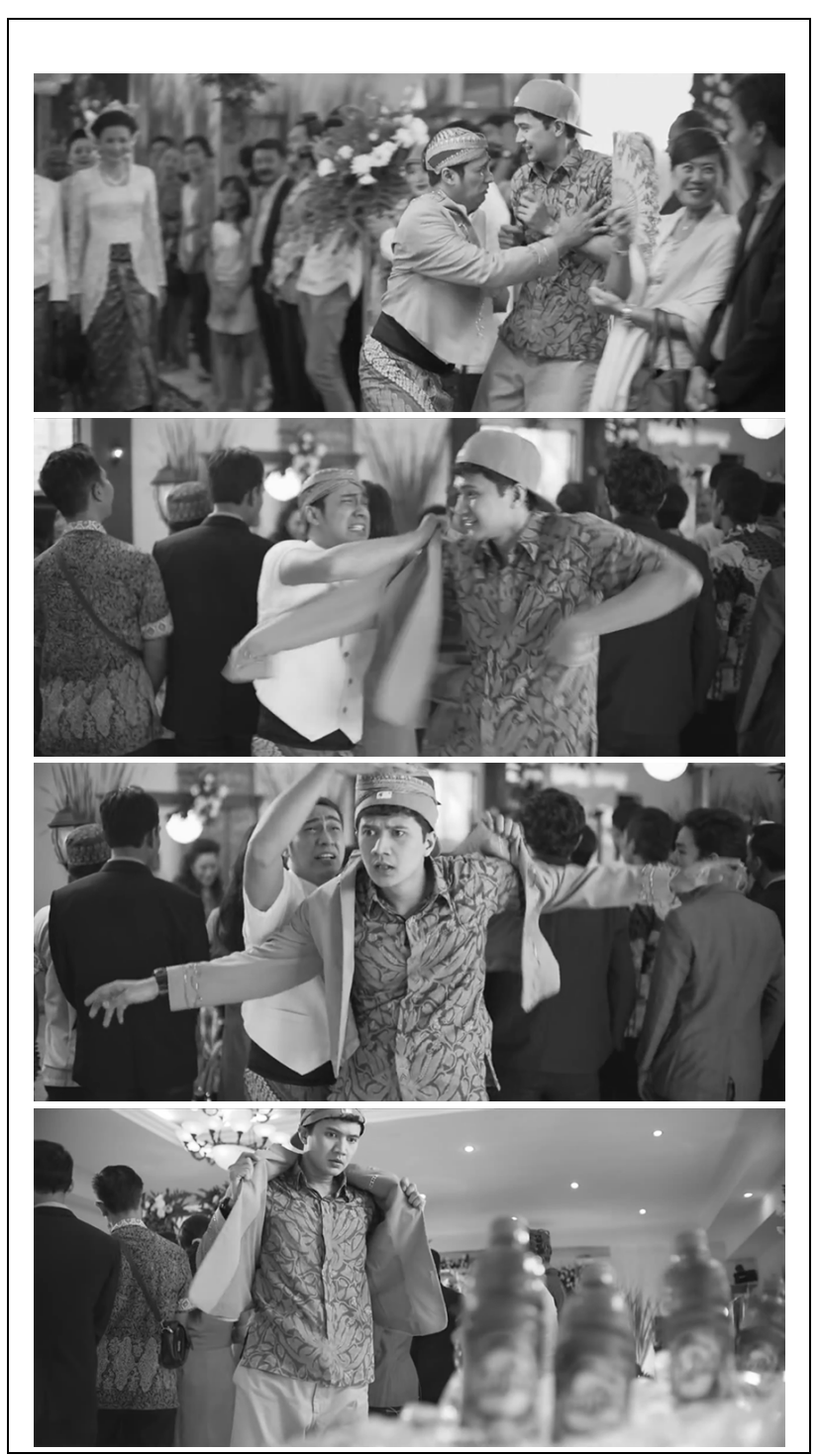

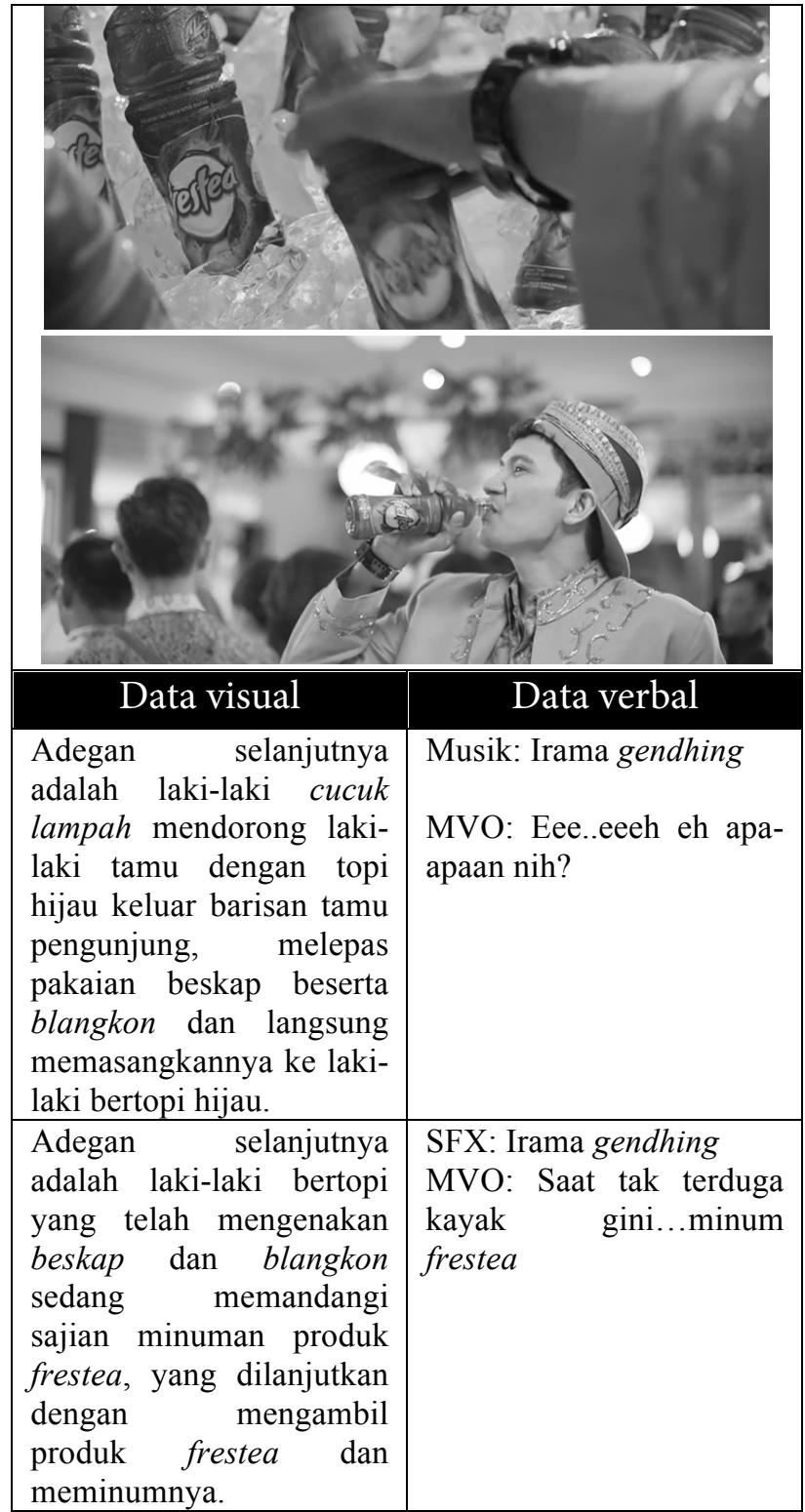

Analisa: Sosok suba manggala melepaskan pakaian beskap dan blangkon yang kemudian dipasangkan pada Firly karena terburu-buru meninggalkan ruangan. Blangkon dipasangkan di atas topi, dan beskap dipasangkan pada baju batik. Tampak bahwa Firly merasa berada dalam kondisi tak terduga dan berkesan tidak nyaman. Firly juga tampak tidak melakukan perubahan posisi blangkon yang ada di atas topinya. Adegan tersebut dapat diartikan: Pertama, menampakkan suatu perubahan makna 
Analisis Wacana Kritis Komodifikasi Budaya Lokal pada Iklan Televisi (Studi kasus Produk Frestea versi Hiphop Wedding)

simbolik yang terdapat pada blangkon karena penempatannya yang tidak lagi mencerminkan nilai-nilai filosofis yang dikandungnya. Kedua, iklan berupaya menciptakan nuansa humor dengan menempatkan blangkon pada topi dikarenakan kondisi yang tidak terduga, sekaligus tidak dirubahnya posisi blangkon di tempat yang seharusnya (tanpa memakai topi) oleh Firly. Ketiga, menampakkan suatu proses pemindahan tugas yang bersifat asalasalan, dari seorang suba manggala kepada Firly sebagai tamu yang, besar kemungkinan tidak memiliki kemampuan untuk melakukan tugas yang baik sebagai penari cucuk lampah.

Sosok Firly yang telah memakai blangkon dan beskap terlihat memandangi produk Frestea sebanyak lima botol yang muncul karena perubahan fokus kamera. Sosok Firly kemudian terlihat blur karena tidak diperlihatkan secara fokus. Kemunculan produk pada adegan ini dapat diartikan bahwa produk Frestea merupakan suatu 'jawaban' atas kebingungan yang dialami oleh Firly. Hal tersebut nampak karena perubahan fokus kamera dari Firly ke arah produk.

Ikon produk Frestea berupa botol yang diletakkan di atas es yang kemudian salah satunya diambil oleh Firly. Penempatan produk ini secara jelas bertujuan untuk menunjukkan identitas dari produk beserta keterangannya yaitu teks "minuman teh beraroma melati", karena ditampakkan secara close up.

Ikon Firly yang meminum produk Frestea dan kemudian merasa bahagia dan segar, yang telihat dari mimik wajah. Adegan tersebut dapat diartikan: Pertama, iklan berupaya menunjukkan benefitnya. Kedua, menampakkan gaya minum yang tidak lazim dilakukan di suatu acara kultural, karena secara umum memakai gelas. Ketiga, menunjukkan fenomena budaya hidangan teh di acara pernikahan adat Jawa.

Tabel 3 Identifikasi data verbal dan visual iklan Frestea versi Hiphop wedding

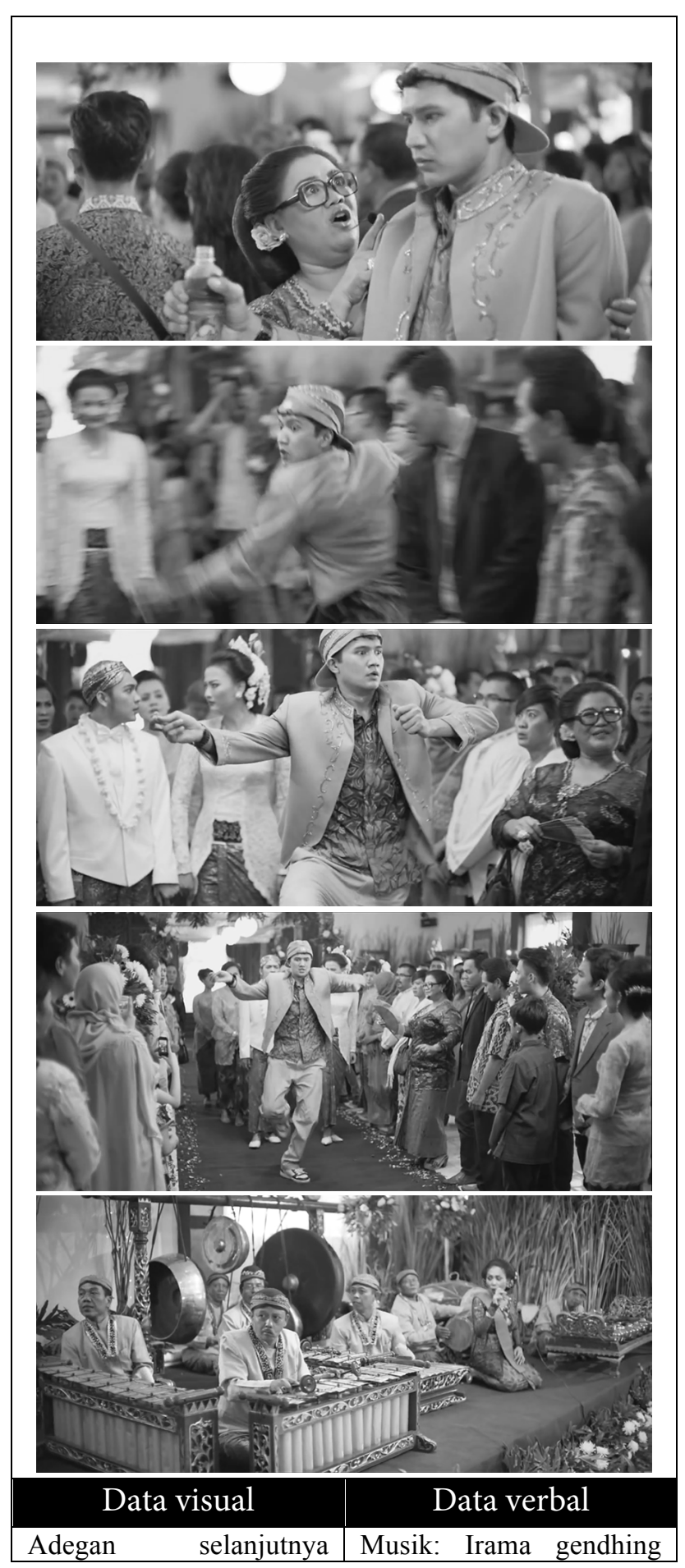




\begin{tabular}{|c|c|}
\hline $\begin{array}{lr}\text { adalah } & \text { seorang } \\
\text { perempuan yang tiba-tiba } \\
\text { memergoki laki-laki } \\
\text { bertopi, } \\
\text { mendorongnya ke arah } \\
\text { barisan pengantin karena } \\
\text { perempuan tersebut } \\
\text { mengira laki-laki bertopi } \\
\text { itu adalah penari. }\end{array}$ & $\begin{array}{l}\text { diiringi nyanyian sindhen } \\
\text { FVO: Mas penari tho? } \\
\text { Ayo sana! }\end{array}$ \\
\hline $\begin{array}{l}\text { Adegan selanjutnya, laki- } \\
\text { laki tersebut terlihat kaget } \\
\text { saat masuk ke barisan } \\
\text { pengantin dan salah } \\
\text { tingkah karena tiba-tiba } \\
\text { harus berperan sebagai } \\
\text { penari, dan akhirnya } \\
\text { menari semampunya. }\end{array}$ & $\begin{array}{l}\text { Musik: Irama gendhing } \\
\text { diiringi nyanyian sindhen }\end{array}$ \\
\hline 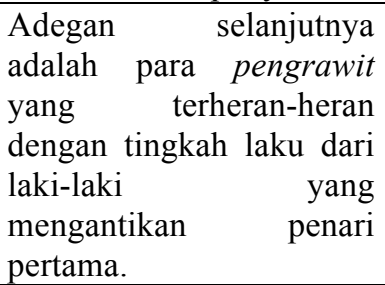 & $\begin{array}{l}\text { Musik: Irama gendhing } \\
\text { diiringi nyanyian sindhen }\end{array}$ \\
\hline
\end{tabular}

Analisa: Sosok Firly yang terkaget karena secara tiba-tiba diajak bicara oleh perempuan bertubuh gemuk, berkacamata dengan frame besar dan tebal, memakai baju kebaya warna merah, dan mengenakan alat komunikasi di bagian wajah sebelah kiri. Baju kebaya mengindikasikan bahwa perempuan tersebut adalah seorang panitia, diperkuat dengan adanya alat komunikasi wireless yang dipakainya. Kehadiran sosok panitia dalam iklan bertujuan untuk menciptakan nuansa budaya pernikahan adat Jawa Tengah yang kuat.

Sosok perempuan panitia menanyakan identitas Firly, karena mengira Firly adalah suba manggala yang seharusnya berada di iringan pengantin, bukan di lokasi tamu/kudapan. Dalam adegan terlihat perempuan panitia bertanya secara tiba-tiba, menampakkan emosi marah dan mendorong Firly ke arah iringan pengantin. Hal tersebut dapat diartikan: Pertama, perempuan panitia merasa bahwa suba manggala tidak melakukan tugas yang semestinya sehingga merasa perlu untuk 'dikembalikan' ke lokasi tugasnya karena acara belum selesai. Kedua, menunjukkan ketidaksopanan dalam berkomunikasi kepada panitia yang lain, dalam hal ini penari cucuk lampah.

Sosok Firly berada di lokasi iringan pengantin, terlihat bingung dan panik, dan kemudian melakukan pose dengan tubuh berdiri, tangan kanan direntangkan dengan jari-jari yang berupaya melakukan gerak jari nyempurit. Tangan kiri berada di bagian depan dada dengan posisi ngepel. Gerak jari nyempurit adalah gerakan tari di mana ujung ibu jari bertemu dengan ujung telunjuk membentuk bulatan dan jari-jari lainnya melengkung mengikuti arah jari tengah. ${ }^{8}$ Pose Firly terlihat seperti gerakan memanah. Dalam adegan ini juga tampak sosok perempuan panitia yang terlihat senang karena merasa melakukan pekerjaannya dengan baik dan kedua pengantin yang bingung dengan adanya sosok cucuk lampah yang berbeda. Adegan ini dapat diartikan bahwa Firly berupaya untuk melakukan suatu gerak tari, namun tidak secara benar karena tidak menguasai teknik dengan baik.

Sosok Firly yang tetap percaya diri meskipun tidak menguasai gerakan tari cucuk lampah dan berimprovisasi dengan melakukan beberapa gerakan semampunya yang setidaknya, merepresentasikan suatu gerak tari tradisional. Hal tersebut dapat diartikan bahwa Firly tetap berupaya menjadi seorang cucuk lampah. ${ }^{8}$ http://gagasa.blogspot.co.id/2012/10/gerak-tari.html. Diakses 22
Oktober 2015 . 
Adegan terlihat berhenti sejenak dan muncul ikon alat musik gamelan dan pesindhen. Alat gamelan yang muncul adalah (dari kiri-kanan searah jarum jam): gender, gong, kendhang, bonang, dan saron. Dari ragam alat, tampak bahwa gamelan yang digunakan bertipe Jawa Tengah, karena tidak menggunakan alat seruling seperti di Sunda dan jumlah bonang yang tidak banyak seperti di Bali. Pesindhen atau sindhen adalah sebutan bagi wanita yang bernyanyi mengiringi orkestra gamelan, umumnya sebagai penyanyi satu-satunya. Sindhen juga disebut waranggana "wara" berarti seseorang berjenis kelamin wanita, dan "anggana" berarti sendiri. Pada zaman dahulu waranggana adalah satu-satunya wanita dalam panggung pergelaran wayang atau pentas klengenan. Pada pergelaran wayang zaman dulu, Sindhen duduk di belakang dalang, tepatnya di belakang tukang denger dan di depan tukang kendhang. Pesindhen yang baik harus mempunyai kemampuan komunikasi yang luas dan keahlian vokal yang baik serta kemampuan untuk menyanyikan tembang. ${ }^{9}$ Kemunculan alat musik gamelan model Jawa Tengah dan pesindhen dalam iklan dapat diartikan bahwa: Pertama, iklan berupaya untuk menampakkan kekhasan budaya (alat) musik dari Jawa Tengah dan penyanyi pengiring yaitu seorang pesindhen di acara pernikahan, di mana pada masa kini dalam acara pernikahan cenderung menggunakan alat musik modern seperti elekton, dangdut atau band. Kedua, (alat) musik gamelan dan pesindhen bertujuan untuk menguatkan

\footnotetext{
${ }^{9}$ https://id.wikipedia.org/wiki/Pesindhen. Diakses 22 Oktober 2015.
}

nuansa budaya Jawa Tengah selain penandapenanda yang telah dijelaskan sebelumnya.

Alat musik gamelan, para pengrawit, dan sindhen menempati suatu panggung kecil dengan ketinggian yang cukup rendah, dengan alas berupa karpet warna merah yang terlihat 'murahan'. Hal tersebut menunjukkan bahwa gamelan berikut pesindhen-nya diposisikan di bawah rata-rata tinggi tubuh manusia. Pada alat musik gender terlihat menggunakan pipa-pipa berwarna putih, yang cukup berbeda dengan alat musik gamelan pada umumnya yang menggunakan material bambu untuk meresonansi suara. Di sekeliling panggung juga terdapat pohonpohon hiasan. Hal tersebut dapat diartikan bahwa dalam iklan, alat musik gamelan dan pesindhen hanya diposisikan sebagai 'hiasan' dalam acara pernikahan, bukan sebagai elemen budaya yang, setidaknya, diberikan perlakukan khusus, misalnya dengan panggung yang lebih tinggi dan dengan material pendukung yang lebih baik agar berkesan elegan.

Tabel 4 Identifikasi data verbal dan visual iklan Frestea versi Hiphop wedding

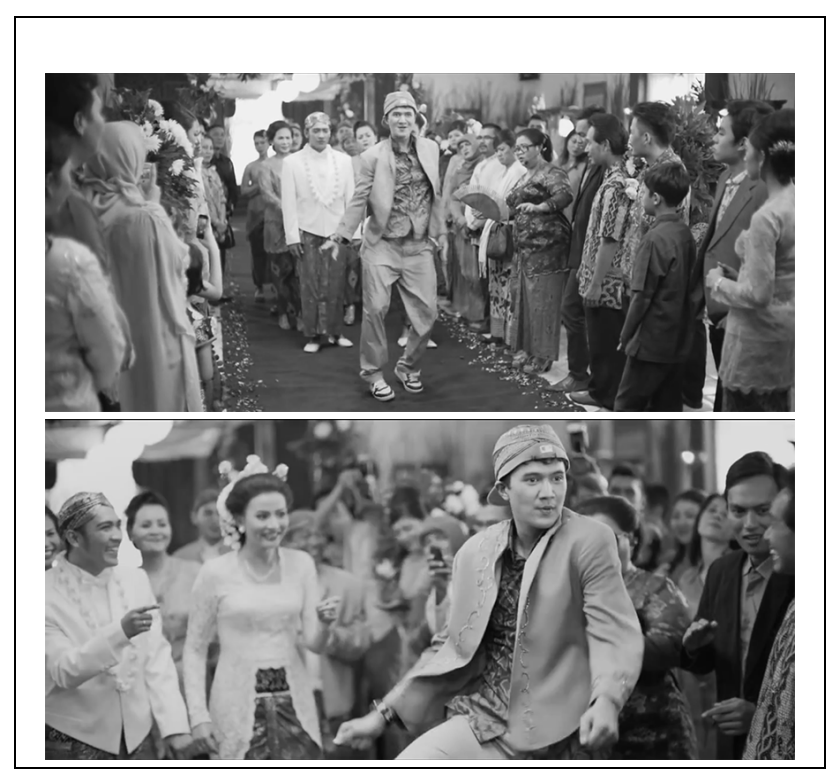




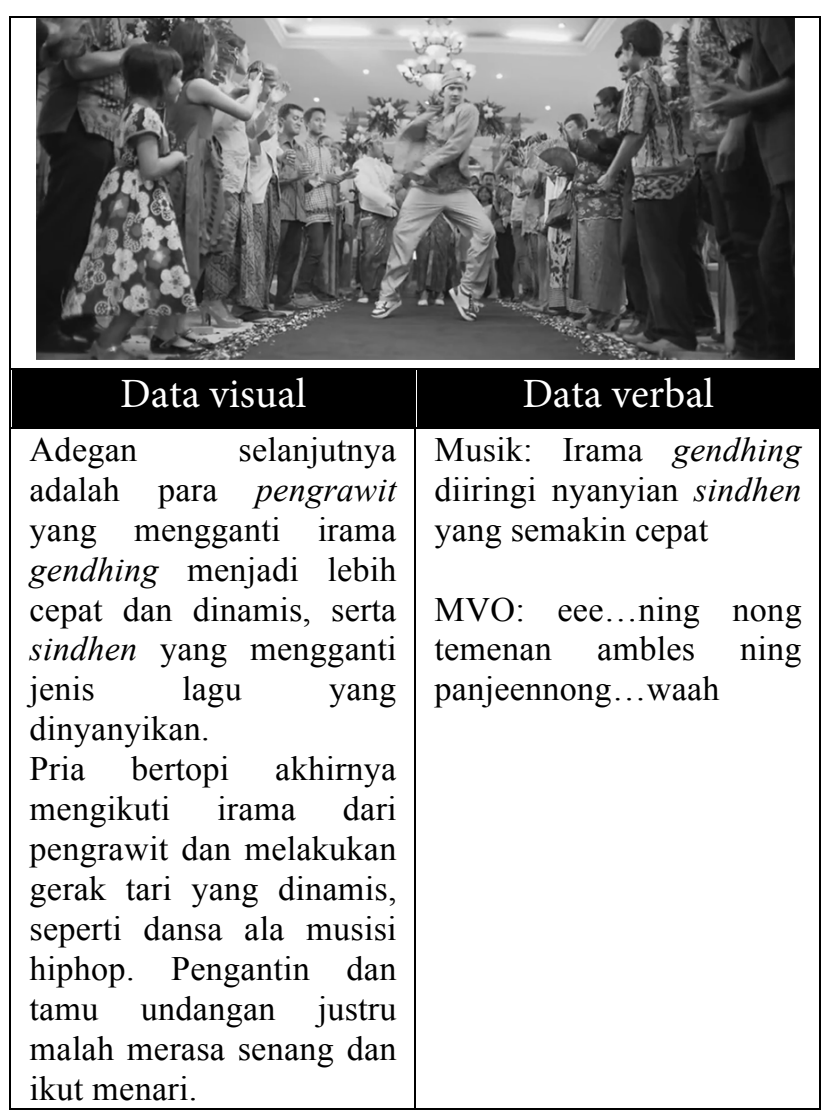

Analisa: Sosok Firly melakukan gerak tari yang identik dengan gaya tari hip-hop (hiphop dance). Hip-hop adalah sebuah gerakan kebudayaan yang mulai tumbuh sekitar tahun 1970'an yang dikembangkan oleh masyarakat Afro-Amerika dan LatinAmerika. Hip-hop merupakan perpaduan yang sangat dinamis antara elemen-elemen yang terdiri dari MCing (lebih dikenal rapping), DJing, Breakdance, dan Graffiti. ${ }^{10}$ Breakdance adalah gaya tari jalanan yang muncul sebagai bagian dari gerakan hip-hop di antara African American dan anak muda dari Puerto Rico yang dilakukan di bagian selatan New York City yang brutal pada tahun 1970. Pada umumnya tarian ini diiringi lagu hip hop, rap, atau lagu remix (lagu yang

\footnotetext{
${ }^{10}$ https://id.wikipedia.org/wiki/Musik_hip_hop. Diakses 22 Oktober
} 2015. diaransemen ulang). ${ }^{11}$ Gaya tari breakdance yang dilakukan oleh Firly terlihat dari gerakan: (1) gerakan bodywave, yaitu gerakan badan yang dinamis, berkesan diombakombakkan dan (2) gerakan armwave, yaitu gerakan pada lengan yang berkesan bergelombang atau diombak-ombakkan.

Perubahan apresiasi dari pengantin dan tamu undangan terhadap sosok Firly yang sebelumnya terlihat bingung, menjadi merasa senang, terhibur dan melakukan gerakangerakan yang lebih dinamis, mengikuti irama gerak Firly. Tampak pula iring-iringan pengantin yang berhenti berjalan. Hal tersebut dapat diartikan: Pertama, improvisasi Firly mengubah suasana dalam acara pernikahan tersebut. Kedua, iklan berupaya menampakkan dinamisasi dalam budaya tradisional, yaitu memadukan antara budaya adat Solo, dengan budaya Barat.

Tabel 5 Identifikasi data verbal dan visual iklan Frestea versi Hiphop wedding

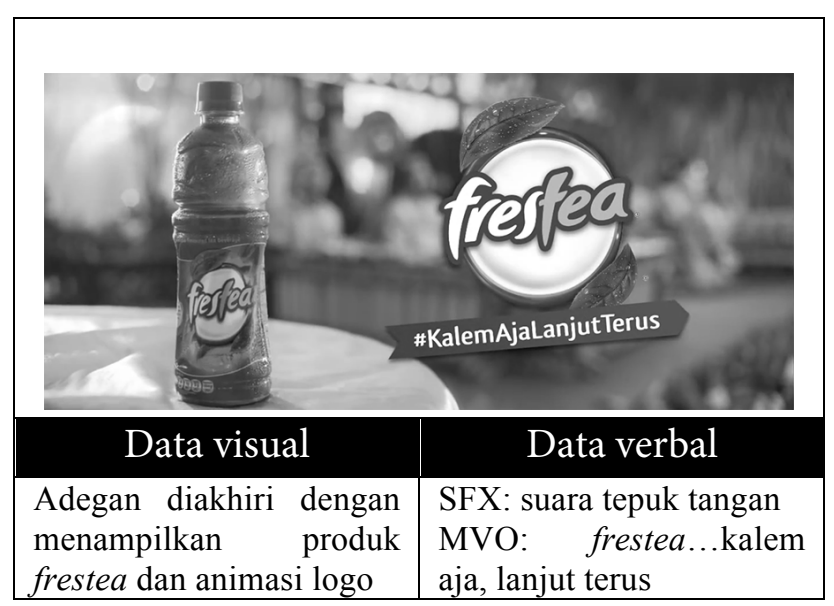

Analisa: Ikon 1 produk Frestea berbentuk botol terisi penuh yang diletakkan di atas meja marmer. Sisi luar botol tampak

${ }^{11}$ https://id.wikipedia.org/wiki/Breakdance. Diakses 22 Oktober 2015. 
adanya butir-butir air untuk menciptakan kesan segar. Alat musik gamelan, para pengrawit dan pesindhen menjadi latar belakang yang ditampilkan dengan teknik blur agar fokus pada produk. Iklan diakhiri dengan adanya animasi logo dan closing word: “\#KalemAjaLanjutTerus”. Komposisi ini dapat diartikan bahwa iklan berupaya memosisikan elemen budaya sebagai elemen sekunder, bukan yang memiliki kesetaraan dengan produk.

\section{KESIMPULAN}

Dari hasil analisis yang dilakukan, dapat disimpulkan bahwa iklan televisi produk Frestea versi Hiphop wedding berupaya untuk melakukan komodifikasi sekaligus kombinasi budaya, yaitu budaya lokal dan Barat. Komodifikasi budaya pernikahan adat Solo terlihat secara dominan pada keseluruhan iklan, mulai dari prosesi pernikahan, busana pengantin, (alat) musik, nyanyian, dan tarian, sedangkan komodifikasi budaya Barat adalah tarian breakdance sebagai manifestasi dari budaya hiphop. Iklan mengkomodifikasi dan mengkombinasikan dua budaya dengan pendekatan parodi, yaitu mengubah budaya tari cucuk lampah menjadi breakdance. Penggunaan sosok Firly merupakan salah satu strategi memanfaatkan public figure yang sedang naik daun, dan dapat menguatkan citra muda pada produk Frestea, yang disimbolkan dengan sikap 'berani melanggar nilai' yang terdapat pada budaya lokal, untuk dikombinasikan dengan budaya asing. Namun demikian, meskipun citra muda hendak dihembuskan oleh Frestea, tampak bahwa simbol-simbol budaya yang diparodikan terlalu ekstrim, sehingga iklan tampak jelas mencoba untuk 'menghilangkan' nilai-nilai filosofis yang terkandung pada simbol-simbol budaya tersebut. Dalam hal ini, dapat dibangun suatu asumsi bahwa iklan Frestea versi Hiphop wedding dapat berpotensi mengajarkan keberanian bagi anak muda sebagai target audiens untuk melanggar pakem-pakem filosofis pada budaya lokal kepada pemirsa.

\section{DAFTAR PUSTAKA}

[1] Barker, C. Cultural Studies Teori dan Praktik (terjemahan: Tim Kunci Cultural Studies Centre). Yogyakarta: Bentang (PT. Bentang Pustaka). 2005.

[2] Bungin, M. Burhan. Konstruksi Sosial Media Massa: Kekuatan Pengaruh Media Massa, Iklan Televisi dan Keputusan Konsumen serta Kritik Terhadap Peter L. Berger \& Thomas Luckmann. Jakarta: Kencana. 2008.

[3] Eriyanto. Analisis Framing: Konstruksi, Ideologi, dan Politik Media. Yogyakarta: LkiS. 2012.

[4] Gee, James Paul., Handford, Michael. (editor). The Routledge Handbook of Discourse Analysis. NY: Routledge. 2012.

[5] Odih, Pamela. Advertising in Modern and Postmodern Times. CA: SAGE Publications Ltd. 2007.

[6] Saragih, Kalam C. T. Analisis Konstruksi Maskulinitas Dalam Advertorial Event Vaseline Men "Band of Bikers" dalam Situs Motorexpertz.com, Motormodif.com, dan Swa.co.id Pada Tahun 2013. Skripsi. ISI Yogyakarta.

[7] Van Dijk, Teun. Discourse and knowledge: a sociocognitive approach. UK: Cambridge University Press. 2014.

\section{Website}

http://www.kompasiana.com http://komunikasi.unsoed.ac.id 